Chapter 16

\title{
Students Collaborate to Develop Educational Green-Clothing Label
}

\author{
Hae Jin Gam, Yoon Jin Ma, Elizabeth Ciaccio
}

\begin{abstract}
Purpose: Increasing consumer awareness of environmental degradation resulting from the textile and apparel industry is vitally important to making corrective efforts to promote more environmentally friendly products. Green labels for textile and apparel products could aid consumers in making environmentally responsible purchasing decisions. The purpose of this project was to develop an informative green label that outlines the impact of a product on the environment, to help inform the consumer considering buying the product.

Approach: This project was conducted in collaboration with university students, employing a three-stage design process as a framework. To develop an informative green label prototype, different aspects of sustainability in the apparel industry were identified; from these, the six symbols conveying the critical aspects of sustainability were developed. Focus group discussions were utilized to obtain preliminary consumer comments on the label and symbol design prototype.

Findings: Six easy-to-read symbols and a clear label layout for prototypes I and II were created. Content analysis of the focus group discussions provided valuable insights into participants' opinions about prototype I. Participants agreed that implementation of standardized symbols and explanations on sustainable apparel products would evoke a more positive reaction from consumers.

Originality/value: Just like the nutrition facts and ingredients description on a food package, our proposed apparel label includes customized information on how the contents of a specific product and its production process impact the environment and the people in it.
\end{abstract}

\section{Introduction}

An eco-labeling system would allow producers and farmers to inform consumers of their sustainable practices. Consumers can then display their support of sus- 
tainable practices by making reflective decisions after reviewing eco-labels on products (Aspers 2008). Effective eco-labeling will reduce information gaps between consumers and producers by assuring consumers that a product is produced in an environmentally friendly way (Van Amstel et al. 2008). Eco-labeling systems can address two consumer segments. The first segment includes green product purchasers who are motivated by eco-labeling (D'Souza 2004). And the second represents green product purchasers who wish to understand which environmental and social impacts are being addressed (Van Amstel et al. 2008). Organic food labeling has been the most successful among various eco-labeling systems (Howard and Allen 2006). However, there is no well-established ecolabeling system for apparel products because these products are less standardized than other product categories due to fast-changing fashion trends (Aspers 2008).

One problem organic clothing products face is that there is no general definition or common understanding of how apparel products can be environmentally friendly (Meyer 2001). Although the apparel industry has significant impacts on the environmental and health problems of the world, this is not widely known by consumers (Chen and Burns 2006). For example, because cotton is a natural fiber, most people assume that it is all natural and safe. However, the cotton industry uses substantial amounts of pesticides and chemicals, and more water for production than any other fiber, making it one of the most detrimental fibers to the environment. Increasing awareness of the environmental impact of the textile and apparel industry and making efforts to promote more environmentally friendly products is critical if the apparel industry is to compete in the ecomarket and contribute to the reduction of environmental impacts.

Marks (2007) revealed that about $69 \%$ of consumers surveyed were willing to buy organic textile and apparel products, depending on pricing and availability. However, there is limited information available to consumers about why it is important to buy environmentally friendly goods, particularly in the case of textiles and apparel products. Various textile eco-label systems do exist, but so far they have failed to become established in industry (Meyer 2001). Green labels on textile and apparel products can greatly assist consumers in making environmentally responsible purchasing decisions (D'Souza et al. 2006). Consumers have expressed a need for the standardization of labels and label symbols, including an easy-to-read numerical rating system (Stern and Ander 2008). Considerable improvements have been made with respect to green labels for food, household cleaners, and wood or paper products, prompting an increase in consumer purchases of those products (Horne 2009; Howard and Allen 2006). For these reasons, it is imperative that a style of "green" labeling for textile and apparel products is developed that is both informative and easy for consumers to understand. Improved consumer knowledge of environmentally friendly apparel and textile products may lead to more informed, ecologically responsible purchases, which in turn will result in more consumers living a sustainable lifestyle and preserving the environment. 
To address this need, our study aimed to create an informative green label for sustainable apparel products. We created a research team consisting of two faculty members and eight university students. The project lasted one semester, and the team members collaborated on three tasks: (1) defining current problems, (2) designing symbols and layouts, and (3) conducting the focus group discussions and analyses. This article describes how the university research team developed a green-clothing label layout and symbol designs for encouraging and assisting consumers in obtaining information about the impact of a product on the environment.

\section{Conceptual Framework}

This study employed a three-stage design process (LaBat and Sokolowski 1999) as a framework to develop the consumer-friendly and informative clothing label. The design process model has three steps: problem definition and research, creative exploration, and implementation. These three steps are sequential events. Problem definition and research engages preliminary and working problems that initiate the next step. The creative exploration step involves idea generation, design refinement, development of prototype, and evaluation of prototype. Implementation connects with the actuality of product production for consumer use. Further refinements can also be realized in this step.

This design process model proposed by LaBat and Sokolowski (1999) was developed for the field of textile and clothing. They utilized the model for a cooperative industry-university project for textile production. This three-stage design process model was selected in our study because the label prototype that was developed will be used for clothing products, and therefore, followed the same design process as textile products. In addition, LaBat and Sokolowski's (1999) model presented common structures not only from the textile and clothing field but also the engineering and industrial fields. Conducting a structural design process, as this model suggests, provides "justification for pursuing the best design solution to the problem" (LaBat and Sokolowski 1999: 19).

\section{Label Development Process}

\section{Step 1: Problem Definition and Research}

One problem in the green apparel industry is the terms and definitions used by companies and marketers to promote green products. These terms are often too vague for average consumers to understand. Terms on clothing labels and tags such as certified organic, recycled, recyclable, post-consumer, and all natural 
can be very confusing for consumers, especially because they can mean different things when used by different companies (Stern and Ander 2008). One company's all natural standard could imply that the product was made with natural organic fibers, while another company's all natural claim could simply mean that it was made with natural fibers such as cotton. Considering the fact that cotton cultivation is still very detrimental to the environment due to the excessive use of synthetic pesticides and insecticides, unclear terms on the product labels and tags may lead to misinterpretation by consumers. A study by Chen and Burns (2006) found that only about 5\% of respondents understood the terms recycled and recyclable in the sense defined by the Environmental Protection Agency and the Federal Trade Commission. Although federal and state governments have helped by issuing standardized uses for some of these terms on apparel labels, consumer interpretations continue to be skewed. Moreover, some consumers are mistrustful of the government agencies providing the label standards and information, so they simply do not believe the claims on the labels (Buono et al. 2002).

Another problem in green apparel is that no common definition or understanding exists for what constitutes environmentally friendly clothing. Although many textile eco-labels exist, none of them has been able to establish itself in industry (Meyer 2001). For example, consumers may find an organic shirt that is labeled organic cotton but the producers may use environmentally toxic dyes or the product is produced by less socially conscious manufacturers (Stern and Ander 2008). Consumers' knowledge about environmental impacts and social responsibility of apparel products is not evenly distributed in society (Aspers 2008), and efforts to reduce this gap should be made.

Finally, several studies show the need for informative eco-labeling of environmentally friendly products. Chase and Smith argued that $70 \%$ of respondents made purchasing decisions based on the environmental messages on product labels and advertising, showing evidence of the importance of informational labels (1992). For apparel products, consumers rarely see the association between their purchasing and social and environmental impacts, but the motivation of consumers to practice sustainability can be encouraged by quality information (Allwood et al. 2008). Ethical and environmental labels for apparel products that contain information can help consumers support sustainable practices through their purchases (Aspers 2008). Based on the problems defined, we conducted a literature review to understand what sustainable practices are executed in the current textile and apparel industry and to identify key sustainability aspects of the apparel products.

The intention of sustainable apparel production and consumption efforts is to anticipate positive changes and a considerable decrease in negative environmen- 
tal and social impacts (Allwood et al. 2008). Poole et al. (2009) suggested that employing renewable materials, using an environmentally friendly and commercially viable process, and having biodegradable or recyclable capabilities are important for being considered eco-friendly in the apparel area. Similarly, Chen and Burns (2006) defined nonpolluting practices as those that obtain, process, and fabricate with renewable, reusable/recyclable, and/or fully biodegradable resources in sustainable textile and apparel production processes. Joergens (2006) also defined ethical fashion as clothes that are made applying fair trade principles, processes not harmful to the environment and workers, and using biodegradable and organic materials. Based on the reviewed literature, this study identified six sustainable clothing characteristics: organic, biodegradable, safely dyed, fair trade, low carbon footprint, and recycled. These aspects emphasize sustainability in clothing in relation to using renewable materials (organic or biodegradable), applying the right processes (safely dyes, fair trade, low carbon foot prints), and encouraging reusing or recycling materials. Table 1 shows a summary of the literature review related to aspects of sustainability in the apparel area. Based on the review, our research team decided to develop six symbols to indicate sustainable apparel design and production practices.

Table 1: Summary of identifying sustainability aspects of apparel products

\begin{tabular}{|c|c|}
\hline Aspect & Why it is important? \\
\hline 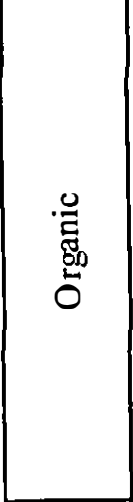 & $\begin{array}{l}\text { Cotton cultivation uses about } 10 \% \text { of the overall amount of synthetic pesticides and about } \\
25 \% \text { of insecticides applied world-wide each year }{ }^{1} \text {. The usage of toxic pesticides and } \\
\text { chemicals, such as formaldehyde, for cotton production generates negative environmental } \\
\text { impacts and health concerns }{ }^{2} \text {. For wool production in the United States in } 2000,14,191 \\
\text { pounds of insecticides were used directly on sheep and lambs }{ }^{3} \text {. The chemicals not only } \\
\text { severely contaminate our land and water supply, but human quality of life is also } \\
\text { threatened. The direct pesticide intake primarily harms farm workers and contributes to the } \\
\text { contamination of drinking water and food. This contamination also causes detriment to } \\
\text { regional habitats. Most environmental impacts of textiles caused by extensive use of } \\
\text { pesticides and chemicals could be alleviated dramatically if cotton and wool producers } \\
\text { switched from traditional production to organic production methods for a sustainable } \\
\text { ecological system }\end{array}$ \\
\hline 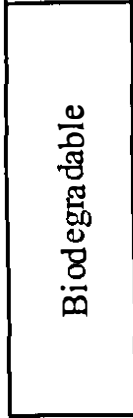 & $\begin{array}{l}\text { Increased cost of petroleum production and consumers' concerns related to environmental } \\
\text { impacts from oil-based fibers both encourage development of alternative fibers. } \\
\text { Biodegradable or bio-based fabrics are being produced to replace petroleum-based fabrics } \\
\text { Instead of using up limited petroleum resources, plants such as corn, beets, wheat, and rice } \\
\text { can subsidized and/or eventually replace fossil fuels and reduce pollution. Bio-based fibers } \\
\text { or biodegradable polylactide (PLA) polymer "requires } 20 \text { - to } 50 \text {-percent less fossil fuel and } \\
\text { generates } 15 \text {-to 60-percent fewer greenhouse gas emissions in its production than petro- } \\
\text { chemical-based fibers such as polyester"7 (p. 66). Considering more than half the amount } \\
\text { of globally produced fibers are currently synthetic, promoting biobased fibers will reduce } \\
\text { the use of these synthetic fibers and facilitate significant environmental benefits }\end{array}$ \\
\hline
\end{tabular}




\begin{tabular}{|c|l|}
\hline Aspect & $\begin{array}{l}\text { Why it is important? } \\
\text { Pollution fromdyeing and printing are of major concern during the apparel production process. } \\
\text { Dyeing and printing of textiles requires a chemical-intensive process and generates a huge } \\
\text { amount of wastewater from operations }\end{array}$ \\
discharged in effluent ${ }^{10}$. In addition, the dyeing process generates environmental problems \\
through the use of heavy metals in dyestuffs and environmentally hazardous chemicals
\end{tabular}

1. Mancini et al. (2008). 2. Chen and Burns (2006). 3. United States Department of Agriculture (2001). 4. Kooistra et al. (2006). 5. Getz and Shreck (2006). 6. Hensler (2006). 7. Rodie (2004). 8. Poole et al. (2009). 9. U.S. Environmental Protection Agency (1996). 10. Blackburn (2004). 11. Ren (2000). 12. Orzada and Moore (2008). 13. Wang et al. (2009). 14. Goig (2007: 469). 15. Rupp (2008). 16. Hertwich and Peters (2009). 17. Anderton (2007). 18. Ramesh (2009). 19. Council for Textile Recycling (n.d.). 20. Black (2009).

\section{Step 2: Creative Exploration: The development of prototype I}

Based on the problems defined, we created a consumer-friendly label as an effective communication tool to promote green apparel products. In order to assist consumers in making an informed purchase decision, we provided the product's sustainable apparel production information on our label. We generated our idea from the widely accepted food nutrition label. Just as the nutrition facts and 
ingredients list on the food package assist consumers in understanding how the food is made to promote healthier lifestyles, our apparel label includes customized information on how the content of a specific product and its production processes impact the environment. This label will enhance consumers' understanding of how the materials and production methods of the apparel product affect the wearer, apparel industry workers, and the environment. In this sense, our label was named, "the In(green)dients label." Green represents sustainable practices, while ingredients represent the healthy materials.

In accordance with the different aspects of sustainability in the apparel area that were identified in step 1, six symbols were created (Fig. 1): 1) organic, 2) biodegradable, 3) safely dyed, 4) fair trade, 5) carbon footprint, and 6) recycled. The self-explanatory symbols are accompanied by brief written explanations for clarification, allowing the label to be easily read and understood and providing a convenient reference for consumers. We utilized a measuring cup for the shape of the label to represent the "ingredients" or materials and processes as well as to illustrate how that product "measures up" to a set of criteria (Fig. 2).

Figure 1: The design of symbols and facts on Prototype I

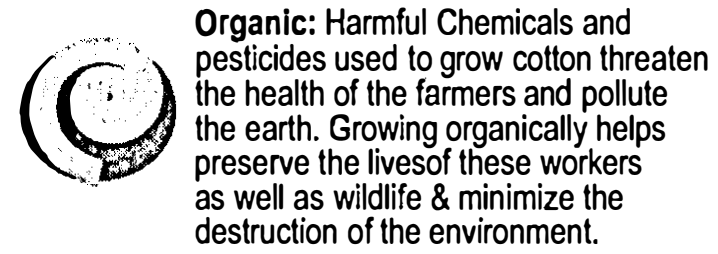

Fair Trade: Fair Trade ensures that the producer is receiving fair pay, living conditions, and working conditions; as well as establishing a long-standing relationsip with them. It also ensures that the product was not made using illegal methods \& labor

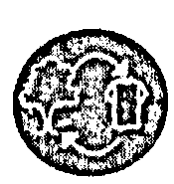

Biodegradable: Biodegradable fibers reduce the concern of what will happen to a product after they will break down \& decompose rather than remain another of earth's harmful pollutants.

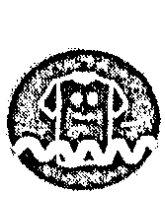

Safely Dyed: Reactive dyes are harmful to environment, often causing respiratory problems\& skin irritations. Safely dying methods help reduce the amount of harm to humans as wellas enviromental pollution.

Carbon Footprint: The average national household produces 7.5 tons of carbon dioxide annually which helps accelerate the issues related to global warming. Carbon footprints measure the amount of carbon dioxide emitted into the air \& the impact it has on the environment.

Recycled: Approximately one million tons of textiles are diposed of each year, polluting the earth. Recycling will help minimize the problem as it is broken down \& reused, save valuable resources, energy, \& landfill space.

The label was developed to be affixed as a hangtag on a garment, with information on both the front and the back. The front of the label includes the appropriate symbols for how a product is made. For example, if an apparel product is produced with organic materials, safe dyes, and fair trade practices, the front page will have three symbols: organic, safely dyed, and fair trade. The back lists 
all six symbols to aid consumers in learning about other possible sustainability aspects of apparel products. In addition, the front contains a green fact regarding the amount of garbage generation, which will draw consumers' attention to the environmental impacts caused by apparel production. The colors chosen for the text on the tag were shades of green and black. Green was chosen because this color is associated with being "environmentally conscious," and black was chosen for easy readability.

Figure 2: Prototype I Front \& Back
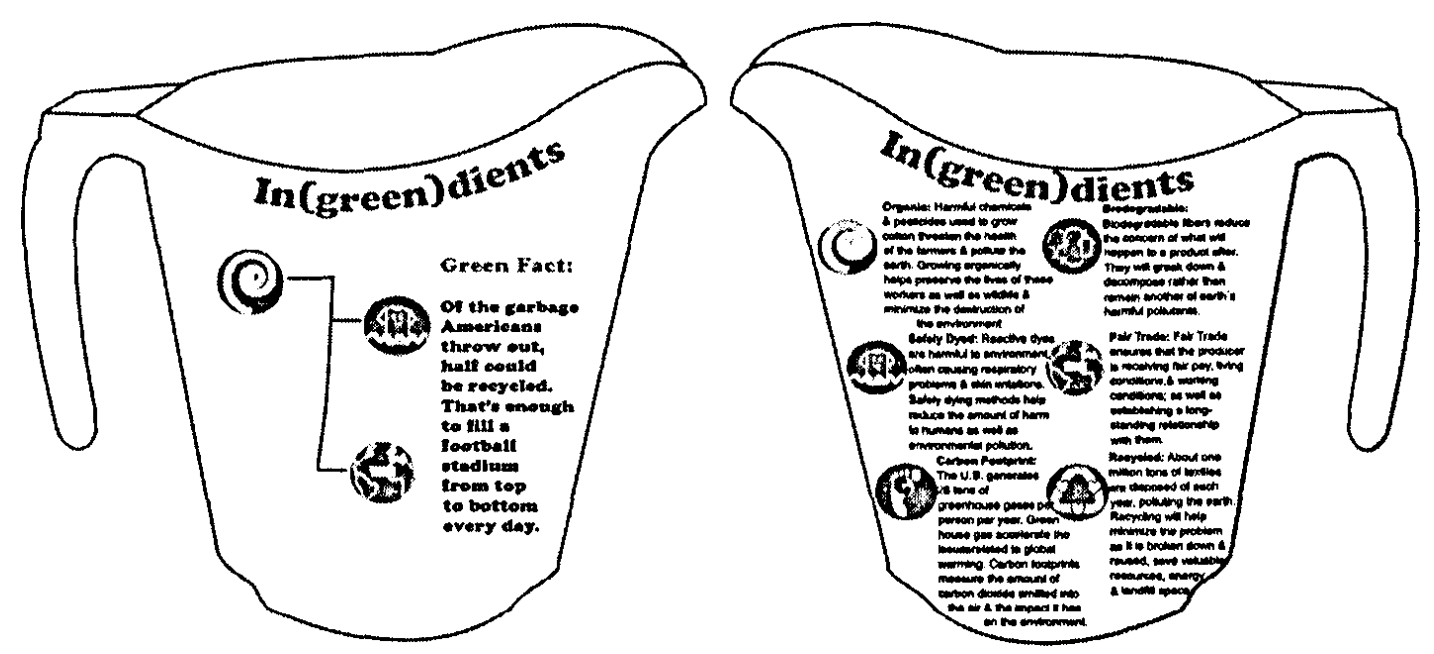

Step 3: Implementation: Focus group discussion

In the framework used, step 3, the implementation stage, explores possible product creation and consumer use. We incorporated a creative visual design for the label with a business and marketing perspective. Not only did we create the attractive label design to maximize consumer attention, but we also assessed current consumer needs and opinions. A series of preliminary focus group discussions were conducted to obtain consumers' opinions about our label design, layout, and information on the Prototype I. Key questions discussed in the sessions concerned the attractiveness, ease of understanding, readability, and purchase intention for the green apparel products with our label. A total of thirtytwo participants were recruited for three focus group sessions using a convenient sampling method from students, faculty, and staff members at a large Midwestern university. Their ages ranged from 19 to 66-years-old, and the majority of them were female $(90.6 \%)$. Using the notes and transcriptions collected from the audio-recorded focus group discussions, researchers conducted a content analysis. All of the participants were given a discussion pseudonym to ensure confidentiality and honest replies. 
Prior to the discussion, a set of color printed copies of prototype I were passed around for each participant to observe the design, layout, and information on the label. Overall, feedback from the focus groups was very positive. The participants expressed doubt about current eco-friendly claims on apparel products, but showed interest in reading our $\operatorname{In}$ (green)dients label. The focus groups provided numerous comments on the layouts and symbol designs of the label.

The majority of the participants agreed that the label was attractive and noticeable, and they also liked the name of label, the "In(green)dients." One participant (Jonathon, 21) commented "Obviously, it's green and I think it should be green. I think the title is really clever and all the little pictures like the footprint with the $\mathrm{C}$ on it .... I actually have to read it to know what it is so it kind of caught my attention to look further into it." Participants favored adapting the measuring cup shape and thought it was more conspicuous because it is not a common shape for a label.

However, another participant (Joyce, 22) said 'I think it's a little overwhelming and that someone who doesn't really care that much wouldn't take the time to read all of this." Nicole, 30 years old, agreed and added comments on using the branches on the front page of prototype I. She said using a branch and placing one symbol higher than the other symbols confused her because she thought one symbol was more important than the other symbols. Four other participants also suggested including green facts in the middle of the measuring cup rather than beside it.

The second question the groups were asked was if the label's symbols and explanations about sustainability were easy to understand. While many participants said that they really liked the symbols, responses to this question varied. Some felt that the symbols were clear, understandable, and witty. Kelly (21) said she liked the smiley face on the t-shirt for the safely dyed symbol. However, more respondents felt that some symbols were confusing. The symbol that caused the most confusion was the organic symbol. Erica (20) had this to say of the symbol, "... the organic one kind of confuses me, like what the swirl would mean ..." Many of the participants felt that if the symbols were established industry-wide, people would be exposed to them more and then would better understand what they meant. One interesting finding was that the participants wanted some statistics (e.g. about one million tons of textiles are disposed of each year) put on the label with brief word explanations to help them visualize the environmental impacts of the apparel industry. This knowledge could stimulate them to be more responsible for what they buy.

The third question asked was if the participants had any suggestions for the label design. Several useful suggestions were made by the groups. One respondent suggested a check mark system on the label to make it clear to the consumer which component symbols were incorporated into the garment. A few participants suggested shortening the symbol descriptions to keep consumers' attention. 
Joyce (22) mentioned "... the paragraphs are just a little too overwhelming ...." Participants also felt that increasing the font size of the symbols' explanations would be a good idea.

The fourth question regarding label design was if the participants would stop and look at this label if it was attached to a garment. It is imperative that consumers' attention is drawn to the label because there are already many promotional tools used throughout the store to distract consumers. Respondents said that the different shape of the label and the symbols would most likely make them stop and look at the label. One participant said a dangling hangtag would grab her attention more than one placed inside the garment. Rita (55) said, "The kids would go, "What is that, a measuring cup?"

The last question posed to the focus groups was whether they would be willing to buy a more expensive green product with this label attached to it and how much more they would be willing to spend. Although the label itself may add value to a product by providing consumer-friendly information regarding the environmental friendliness of the product, it may not be marketable if consumers do not want to pay more for the products because of the label. A prominent concern of the respondents was what the clothing looked like. Respondents agreed that they would not buy a less attractive organic garment with the label attached to it over a more attractive non-organic product. However, participants also mentioned that the label would create more interest and motivation in them to buy organic products. The groups said that they felt a price increase of between 15 and 30 percent was fair for a garment with this label attached.

The participants also suggested developing additional promotional materials, such as a poster presenting the symbol explanations. Most participants felt that implementation of standardized symbols and explanations of organic/"green" product labels would evoke a more positive reaction from consumers when contemplating purchasing organic and other environmentally friendly products. Sarah (66) said "I know a lot of times a company has a cause it supports, but sometimes if you haven't had access to that literature or haven't read it, it may not be available at the site of purchase so sometime you just don't really connect the two or are unaware that this company has these goals." She mentioned why conducting this research is valuable. Participants also stated that if the system of the In(green)dients label is settled in the marketplace, it will become more effective at informing consumers. Andrea (52) said “... I think this would take some education but once you learn the symbols it would be very easy then to know what part of this product or what makes this product organic so I think that would be a great idea." 


\section{Results}

Revised symbols and layout for development of prototype II

The focus group discussions provided us with consumers' diagnostic opinions on the In(green)dients label. We modified the In(green)dients label design prototype I based on participants' feedback and created prototype II (Fig. 3). While modifying prototype I, we examined the possible materials that could be used for mass production of the label. While the main objectives focus on the label layout for its consumer-friendly and informative design, the In(green)dients label itself must be made of environmentally friendly materials. One possible material was paper and, in particular, this study considered flower seed paper. Consumers may tend to throw away a clothing hangtag directly after purchasing a product instead of recycling or reusing them. Flower seed paper, paper that has been processed so it is environmentally friendly and contains flower seeds in it, was selected for our In(green)dients label material because our label can be planted rather than going to a landfill.

Figure 3: $\quad$ Prototype II Front \& Back
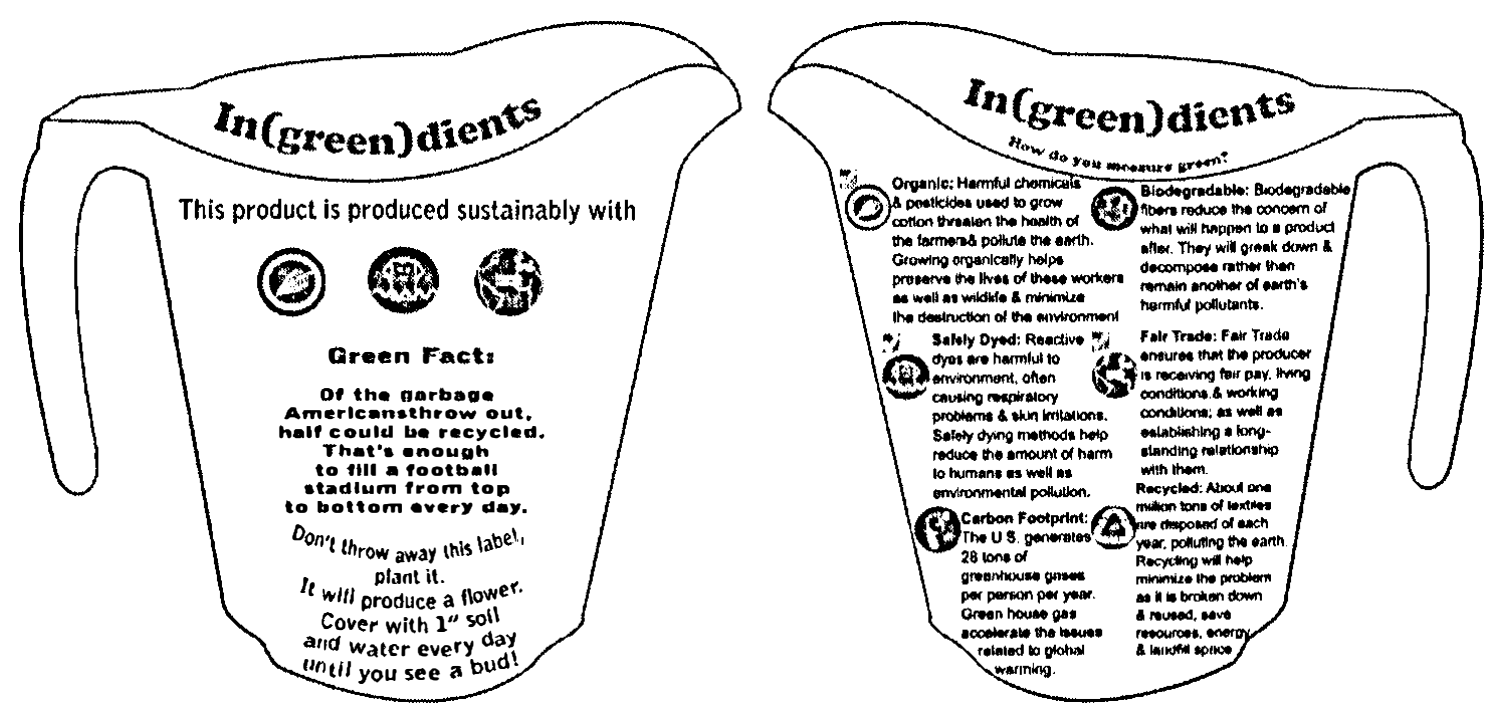

On prototype II, we added the sentence "This product is produced sustainably with" followed by the symbols related to the product. Also, the front has a green fact and the explanation of the flower seed paper the label is printed on. We placed the green fact in the middle of the measuring cup as the focus group suggested. The back of the label presents all six symbols with a check mark added if that specific concept of sustainability is incorporated into the product and its manufac- 
turing process. In addition, we placed the name of the label, In(green)dients, at the top of the measuring cup to maximize use of the limited space. We also modified the design of the organic symbol because it was found from the focus group discussions that the symbol seemed to confuse consumers. The sustainability explanation information was also modified, making it a bigger, easy-toread, font.

\section{Conclusions}

This study developed the consumer-friendly, informative label to provide consumers with information about the sustainability aspects of apparel products. University faculty and students collaborated to develop the label layout and symbol designs. By working with students, faculty can gain innovative ideas to approaching a research project, and the experience incorporates sustainability into the university curriculum.

The label developed in this study was evaluated by focus groups. Participants in the focus group discussions agreed that our In(green)dients label will increase consumers' awareness and knowledge of the environmental impacts of apparel production and foster consumers' green apparel purchasing behaviors. Constructive feedback from the focus group discussions made it possible for us to develop prototype II. The easy-to-interpret symbols on the In(green)dients label will encourage consumers' interest in green products and educate consumers about the effects of the products on our environment. By being more knowledgeable about green products, consumers will be able to make more informed purchases of environmentally responsible products.

The current study has some limitations. We identified six sustainable aspects to be represented by symbols on the label, but determination of which symbols are related to a specific product has to rely on the information provided by the manufacturers and retailers. The textile industry applies a large variety of chemicals, and for only a few of these chemicals is environmental impact information available (Ren 2000). Evaluating the ecological sustainability of individual materials and products is beyond the scope of this proposed project. In addition, because the textile and apparel industry makes continuous efforts to improve technology geared towards sustainability development, there will be more sustainable practices available for textile and apparel products. As sustainability issues evolve, the definition of each symbol will need to be refined. Some focus group participants also suggested that obtaining third party certified symbols might increase consumers' confidence in the reliability of the information. Increasing credibility of the label by obtaining third party certified symbols and collaborating 
with a third party will be a component of future research. Although we obtained consumers' responses on the label through a series of focus groups, their opinions are of limited value in terms of generalizability to consumers as a whole. In the future, the effectiveness of the In(green)dients label should be evaluated in real retail settings. Collaboration with apparel retailers that carry sustainable apparel products is suggested.

This project intends to contribute to the education of consumers by creating an informative green label. There are a variety of ways to educate consumers. Further studies are needed to identify additional marketing and information disseminating methods, such as educational catalog development and/or creation of an informative website, specifically for green apparel products. Research about sustainable textiles and environmentally friendly purchase behaviors is a relatively new concept and will bring challenges as well as many opportunities for future studies.

\section{References}

Allwood, J.M., Laursen, S.E., Russell, S.N., Malvido de Rodriquez, C. and Bocken, N.M.P. (2008), "An approach to scenario analysis of the sustainability of an industrial sector applied to clothing and textiles in the UK". In Journal of Cleaner Production, vol. 16 (12), pp. 633-638.

Anderton, E. (2007), "Step by step: Reducing carbon footprint". In Quality World, vol. 33 (7), pp. 28-31.

Aspers, P. (2008), "Labeling fashion markets". In International Journal of Consumer Studies, vol. 32, pp. 633-638.

Black, S. (2008), Eco-Chic the Fashion Paradox. Black Dog Publishing Limited, London, UK.

Blackburn, R. (2004), "Natural polysaccharides and their interactions with dye molecules: Applications in effluent treatment". In Environmental Science and Technology, vol. 38, pp. 4905-4909.

Buono, J., Hermann, M., Newman, F., Peavey, S. and Teisl, M.F. (2002), "Consumer reactions to environmental labels for forest products: A preliminary look". In Forest Products Journal, vol. 52 (1), pp. 44-50.

Chase, D. and Smith, T.K. (1992), "Consumers keen on green but marketers don't deliver". In Advertising Age, vol. 63, pp. S2-S4.

Chen, H-L. and Burns, L.D. (2006), "Environmental analysis of textile products". In Clothing and Textiles Research Journal, vol. 248 (3), pp. 248-261.

Council for Textile Recycling (n.d.). Available at http://textilerecycling.org. 
D'Souza, C. (2004), "Ecolabel programmes: A stakeholder (consumer) perspective". In Corporate Communications: An International Journal, vol. 9 (3), pp. 179-188.

D'Souza, C., Taghian, M. and Lamb, P. (2006), "An empirical study on the influence of environmental labels on consumers". In Corporate Communications: An International Journal, vol. 11 (2), pp. 162-173.

Getz, C. and Shreck, A. (2006), "What organic and fair trade labels do not tell us: towards a place-based understanding of certification". In International Journal of Consumer Studies, vol. 30 (5), pp. 490-501.

Goig, R.L. (2007), 'Fair trade and global cognitive orientation: A focus on Spanish fair trade consumers". In International Journal of Consumer Studies, vol. 31 (5), pp. 468-477.

Hensler, C. (2006), "Biobased fabric composting trial". In BioCycle, vol. 47 (5), pp. 50-51.

Hertwich, E.G. and Peters, G.P. (2009), "Carbon footprint of nations: A global, trade-linked analysis". In Environmental Sciences and Technology, vol. 43 (16), pp. 6414-6420.

Horne, R.E. (2009), "Limits to labels: The role of eco-labels in the assessment of product sustainability and routes to sustainable consumption". In International Journal of Consumer Studies, vol. 33, pp. 175-182.

Howard, P.H. and Allen, P. (2006), "Beyond organic: Consumer interest in new labeling schemes in the Central Coast of California". In International Journal of Consumer Studies, vol. 30 (5), pp. 439-451.

Joergens, C. (2006), "Ethical fashion: Myth or future trend?" In Journal of Fashion Marketing and Management, vol. 10 (3), pp. 360-371.

Kooistra, K., Pyburn, R. and Termorshuizen, A. (2006), The sustainability of cotton: Consequences for man and environment. Report Number 23.Sciences Shop, Wageningen, UR. Available at http://library.wur.nl/way/bestanden/clc/ 1798712.pdf.

LaBat, K.L. and Sokolowski, S.L. (1999), "A three-stage design process applied to an industry-university textile product design project". In Clothing and Textiles Research Journal, vol. 17 (1), pp. 11-20.

Mancini, F., Termorshuizen, A.J., Jiggins, J.L.S. and van Bruggen, A.H.C. (2008), "Increasing the environmental and social sustainability of cotton farming through farmer education in Andhra Pradesh, India". In Agricultural System, vol. 96, pp. 16-25.

Marks, $J$. (2007), Eco-friendly merchandising on the rise. In Today Home Textiles. Available at http://www.allbusiness.com/marketing-advertising/marketresearch-analysis-market/6351641-1.html. 
Meyer, A. (2001), "What's in it for the customers? Successfully marketing green clothes". In Business Strategy and the Environment, vol. 10, pp. 317-330.

Organic Trade Association (2008), Organic Trade Association's 2007 manufacturer survey. Available at http://www.ota.com/pics/documents/2007Executive Summary.pdf.

Orzada, B. and Moore, M.A. (2008), "Environmental Impact of Textile Production". In Hethorn, J. and Ulasewicz, C. (eds.), Sustainable Fashion: Why Now? pp. 299-325. Fairchild Books, Inc., New York, NY.

Poole, A.J., Church, J.S. and Huson, M.G. (2009), "Environmentally sustainable fibers from regenerated protein". In Biomacromolecules, vol. 10 (1), pp. 1-8.

Ramesh, D. (2009), "Japan announces guidelines for carbon footprint program". In Chemical Week, vol. 171 (8), p. 21.

Ren, $X$. (2000), "Development of environmental performance indicators for textile process and product". In Journal of Cleaner Production, vol. 8, pp. 473481.

Rodie, J.B. (2004), “Corn into gold”. In Textile World, vol. 154 (8), p. 66.

Rupp, J. (2008), "Ecology and economy in textile finishing". In Textile World, vol. 158 (6), pp. 38-41.

Stern, N.Z. and Ander, W.N. (2008), Greentailing and other revolutions in retail. Wiley, Hoboken, NJ.

The Hartman Group (2006), Organic 2006: Consumer attitudes \& behavior, five years later \& into the future. Available at http://www.hartman-group.com/ publications/view/19.

United States Department of Agriculture (2001), Agricultural chemical usage 2000 sheep and sheep facilities. Ag Chem 1 (01). Available at http://usda.mann lib.cornell.edu/usda/current/AgChemUsageSheep/AgChemUsageSheep-0523-2001.pdf.

U.S. Environmental Protection Agency (1996), Best management practices for pollution prevention in the textile industry. EPA Manual 625-R-96-004. Available at http://www.p2pays.org/ref\%5C02/01099/0109900.pdf.

Van Amstel, M., Driessen, P. and Glasbergen, P. (2008), "Eco-labeling and information asymmetry: A comparison of five eco-labels in the Netherland". Journal of Cleaner Production, vol. 16 (3), pp. 263-276.

Wang, L., Li, F. and Feng, H. (2009), "Dyeing of flax fabric with natural dye from chestnut shells". Pigment and Resin Technology,vol. 38 (6), pp. 347-352. 